\title{
Российская редкоземельная промышленность: следует ли перенять опыт Китая? ${ }^{1}$
}

\author{
Я.В. КРЮКОВ, кандидат экономических наук, \\ Н.Ю. САМСОНОВ, кандидат экономических наук, \\ В.А. ЯЦЕНКО, Институт экономики и организации промышленного \\ производства СО РАН, Новосибирск
}

Важнейшая черта политики Китая при развитии национальной редкоземельной промышленности состоит в создании производственных цепочек «от сырья к высокотехнологичному изделию» в рамках ориентации исключительно на внутренний спрос. Перед Россией в настоящее время стоит проблема выбора пути развития редкоземельной промышленности, и потому опыт Китая, который за последние 30 лет накопил значительные компетенции в этой области, представляет несомненный интерес. В особенности это актуально в контексте начала освоения Томторского ниобий-редкоземельного месторождения. Однако, по мнению авторов, российский подход должен отличаться гибкостью и сочетать различные инструменты промышленной и торговой политики. Представляется, что внедрить в России используемые в Китае инструменты такой политики было бы затруднительно из-за национальной специфики и различных стартовых условий построения редкоземельной отрасли. Акцент должен делаться на вхождение в глобальные цепочки производства высокотехнологичной продукции, первым значимым шагом к которому должно стать стимулирование внутреннего спроса на высокотехнологичные изделия и их компоненты. И в этой части опыт Китая мог бы быть полезен.

Ключевые слова: редкоземельные металлы, Китай, высокотехнологичные изделия, стимулирование спроса, промышленная политика, инновации, технологическая цепочка

Рынок редкоземельных металлов (РЗМ) является одним из самых молодых товарных рынков в мире и растет достаточно быстрыми темпами, по сравнению с другими базовыми металлами (никель, медь, железо и др.): за прошедшие 50 лет объем мирового производства и потребления РЗМ увеличился примерно в 27 раз с 5 до 135 тыс. т в год. Это стало следствием как глобального экономического роста, так и эволюции технологических циклов, основанных на волнах новых технологий и инновационном развитии мировой экономики и общества. Объем производства

\footnotetext{
${ }^{1}$ Исследование выполнено при финансовой поддержке РФФИ в рамках научного проекта 17-06-00231/18 «Исследование и определение роли государства при стимулировании и формировании спроса на редкоземельные металлы для высокотехнологичных отраслей отечественной промышленности в условиях неопределённости»
} 
и потребления РЗМ является одним из индикаторов развития той или иной национальной промышленности и четким показателем ее технологичности и инновационной составляющей.

По оценкам Всемирного банка, именно редкоземельные металлы в последнее десятилетие вызывают наибольшую озабоченность в развитых странах в связи с неопределенностью в обеспечении этим видом сырья и значением редкоземельных металлов для передовых промышленных технологий [Pecht et al, 2012]. Неопределенность во многом обусловлена и политическими причинами. По всей видимости, ни один другой вид полезных ископаемых (кроме топливно-энергетических ресурсов) не переплетен с геополитикой настолько сильно, как редкоземельные металлы. Это объясняется безусловным доминированием Китая во всей глобальной технологической цепочке добычи и переработки этого вида сырья и в создании инновационной продукции на его основе.

В последние годы резко возросло беспокойство стран-потребителей Р3М из-за отказа Китая продавать редкие земли на мировом рынке под официальными предлогами возможных экологических проблем, связанных с разработкой месторождений, и резервирования ресурсов для будущего внутреннего потребления. На самом деле (с точки зрения прагматичной научно-технологической и экономической политики) это объяснялось скорее стремлением китайских государственных и частных компаний сконцентрировать технологии, ноу-хау, а также локализовать высокотехнологичное производство на своей территории. Недовольные потребители редкоземельных металлов получили из Поднебесной простой и жесткий совет: «Иди, найди свои Р3М». Вряд ли в связи с этим следует обвинять Китай в нарушении правил международной торговли. Последние не исключают стремление добывать РЗМ не столько с целью получения upstream-дохода или роста политического влияния, сколько для обеспечения внутренних потребностей собственной экономики [Baracos et al, 2016].

Россия занимает второе место по подтвержденным запасам редкоземельных металлов, но производство их внутри страны составляет лишь около $2 \%$ мирового, а потребление - менее $1 \%$. Поэтому анализ проблем, связанных с развитием редкоземельной отрасли в России, требует не только рассмотрения источников 
получения РЗМ, но и изучения механизмов функционирования соответствующих рынков в рамках всей производственной цепочки («от лопаты до оксидов, индивидуальных металлов, их сплавов и далее - к высокотехнологичной продукции») [Самсонов и др., 2016].

Такому аспекту в государственных программах развития отечественной промышленности и инновационного развития, корпоративных стратегиях, экономических научных публикациях не уделяется достаточного внимания. Между тем нам предстоит не только повысить востребованность РЗМ в отечественной промышленности (как с точки зрения объемов, так и в отношении возможностей перспективного применения в новых высокотехнологичных продуктах). В течение ближайших нескольких лет планируется увеличение отечественной добычи редкоземельных руд (Томторское и другие месторождения и источники РЗМ-сырья) и получение из них редкоземельной продукции с добавленной стоимостью (прежде всего, оксиды индивидуальных металлов).

Решением этих взаимосвязанных задач является не только создание собственного производства РЗМ, но и разработка и наладка выпуска инновационной продукции и компонентов с использованием отечественных редкоземельных металлов. Эта цель может достигаться применением довольно широкого набора инструментов - от развития специализированного кадрового состава до создания сети инновационных центров (технопарков, индустриальных площадок), в которых могли бы создаваться новые точки высокотехнологичного роста в национальной экономике, основанные на использовании редкоземельных металлов. Успех этого процесса в значительной мере определяется стимулированием создания в российской экономике значимого количества высокотехнологичных предприятий и компаний частного сектора, а не только государственных.

России необходимо формировать собственный портфель методов стимулирования внутреннего спроса на РЗМ-сырье. При всей успешности стратегии Китая опыт этой страны может быть использован для России только в ограниченной мере. Причины этого следующие:

1) Китай обладал (и до сих пор обладает) монопольным положением на мировом рынке РЗМ и возможностью влиять 
на цены редкоземельной продукции в рамках полной технологической цепочки;

2) развитие китайской редкоземельной промышленности с момента ее создания в 1970-е годы шло «снизу вверх» (от разрозненных небольших артелей и компаний к крупным объединениям), тогда как в СССР на тот момент уже существовала устойчиво функционирующая редкоземельная отрасль, которая позже была подвергнута рыночной трансформации.

Однако опыт Китая в области локализации высокотехнологичных производств в сочетании с мерами стимулирования и протекционизма заслуживает внимания и может быть использован для развития современной российской РЗМ-промышленности.

\section{Редкоземельная отрасль Китая - причины успеха}

В 1992 г. архитектор китайского «экономического чуда» Дэн Сяопин заявил: «На Ближнем Востоке есть нефть, в Китае есть редкая земля». В том же году Госсовет Китая одобрил создание зоны промышленного развития высоких технологий Баотоу. В 1999 г. председатель КНР Цзян Цзэминь отмечал важность «развития и применения редкоземельных элементов для того, чтобы перевести ресурсное преимущество в экономическое превосходство» [Jung et al, 2012].

Китай успешно реализует политику локализации производств на своей территории изделий на основе РЗМ с высокой добавленной стоимостью. Страна в короткие сроки сконцентрировала более 97\% мощностей по добыче и переработке РЗМ, располагая при этом только $30 \%$ ресурсной базы мира. Политика Китая заключается в поддержании высокого спроса на РЗМ внутри страны, что делает экономически обоснованным формирование предложения - добычу и переработку РЗМ до чистых оксидов и сплавов. Возникает вопрос: какие уроки из достижений Китая могла бы извлечь Россия, чтобы создать свой внутренний спрос и расширить производство изделий с высокой добавленной стоимостью на основе собственных РЗМ?

Большинство редкоземельных предприятий Китая расположены вблизи крупных редкоземельных шахт, таких как Баотоу во Внутренней Монголии, Мяннинг в провинции Сычуань 
и Ганьчжоу в провинции Цзянси. Таким образом, нет значительного территориального разделения между добычей и обогащением. Между тем отрасль по производству РЗМ в Китае географически разделена на два блока. Предприятия «северного» блока специализируются на РЗМ легкой группы: редкоземельные концентраты, сплавы, редкоземельные соединения, высокочистые металлы, а также такие продукты, как полирующий порошок и магниты. Предприятия «южного», в свою очередь, ориентированы на выпуск средних и тяжелых редкоземельных элементов, включая различные высокочистые редкоземельные соединения и металлы, концентраты, смешанные металлы и сплавы.

Стремление Китая к мировому технологическому лидерству в редкоземельной промышленности может быть проиллюстрировано на примере создания производства неодимовых сверхсильных постоянных магнитов, активно применяемых в производстве современных ветряных турбин, гибридных автомобилей, электромобилей (за последние 30 лет объем использования неодима для производства среднего автомобиля вырос с 1 кг до 8 кг). В 1986 г. американская компания General Motors коммерциализировала изобретение в 1982 г. неодимовых магнитов, создав компанию Magnequench в штате Индиана. В 1995 г. две китайские компании приобрели Magnequench. В соответствии с условиями сделки в течение следующих пяти лет производство магнитов оставалось в Индиане, а в штате Северная Каролина был открыт технологический центр. Но в 2001 г., после того, как были выполнены контрактные условия, производство из Индианы было перемещено в Китай на завод в г. Тяньцзин. В 2004 г. технологический центр из Северной Каролины был переведен в Сингапур, и США тем самым утратили лидерство в производстве неодимовых магнитов ${ }^{2}$. Сегодня Китай - безусловный мировой лидер в этой сфере и контролирует практически всю технологическую цепочку их производства с высокой добавленной стоимостью (рыночные цены на входные и выходные компоненты при выпуске магнитов отличаются почти в 20 раз) (рис. 1).

\footnotetext{
2 "Neo Material Technologies" NEO Material Technologies Inc. - Homepage. NEO Material Technologies Inc.URL: <http://www.magnequench.com/>
} 
Доля Китая в мире:

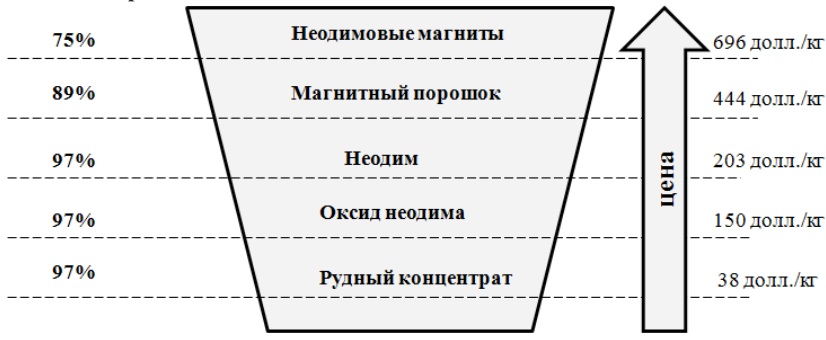

Puc. 1. Создание добавленной стоимости при производстве неодимовых магнитов-место Китая

\section{Особенности становления редкоземельной промышленности в Китае}

Политика Китая в отношении управления поставками редкоземельных металлов на мировой рынок и в конкретные страны постепенно эволюционировала по следующим взаимосвязанным направлениям (рис. 2):

- от ориентации преимущественно на экспорт РЗМ (при этом индивидуальные оксиды и чистые металлы встраивались в горизонтальные цепочки в промышленных секторах уже других стран) до ограничения экспорта и развития внутренних технологических цепочек полного цикла в Китае;

- от регулирования экспорта РЗМ к стимулированию спроса на редкоземельные металлы внутри страны.

Важнейшим инструментом Китая при становлении РЗМ-отрасли в первом десятилетии XXI века являлся протекционизм - экспортные пошлины на РЗМ были отменены только после того, как экономика достигла достаточного уровня развития внутреннего высокотехнологичного производства. Монопольное положение также дало возможность искусственно занижать цены внутри страны, чтобы стимулировать локализацию производств зарубежных компаний в Китае.

В настоящее время редкоземельная отрасль Китая реорганизуется для решения проблем, связанных с низкой консолидацией производств и снижения экологической нагрузки. В 2014 г. был утвержден план создания шести новых корпораций по добыче и производству РЗМ. 


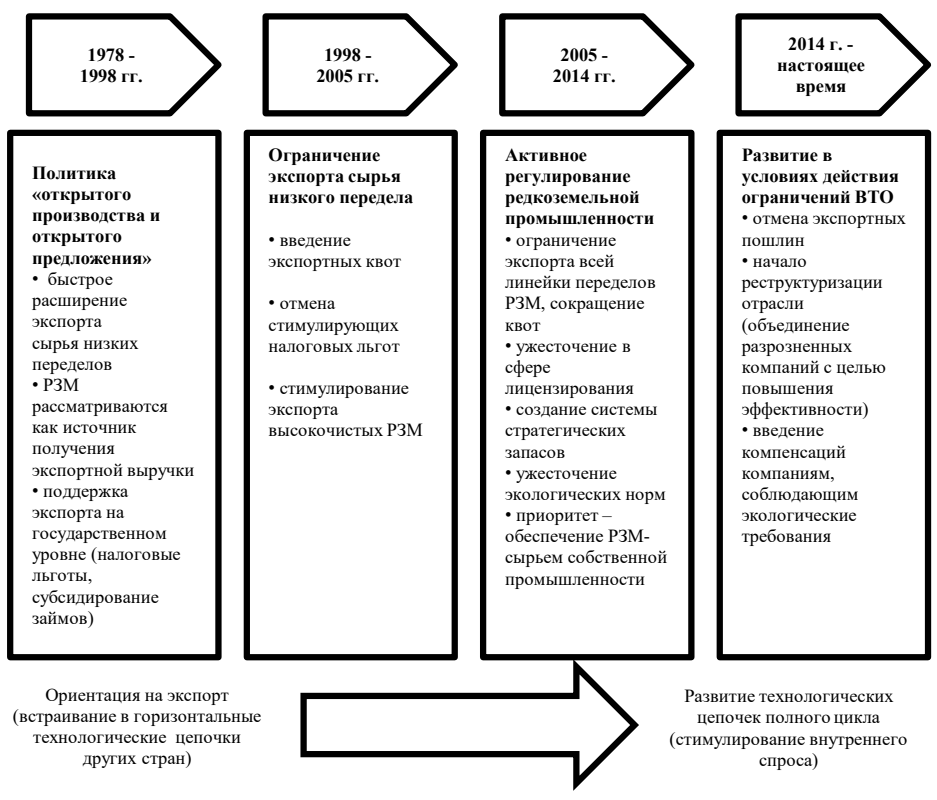

Puc. 2. Эволюция политики Китая в отношении редкоземельной промышленности в 1978-2018 гг.

Правительство предоставило четырем крупным компаниям значительные кредиты для проведения консолидации и скупки более мелких предприятий. Также введен в действие ряд законодательных мер для финансовой поддержки добычи РЗМ и инновационных отраслей-потребителей РЗМ. В частности, были введены разовые компенсации горнодобывающим компаниям, прошедшим экологические проверки: 1000 юаней - за тонну добытой руды, 1500 юаней - за обогащение и разделение, 500 юаней - за производство PЗМ [Lei et al, 2017]. Это дало определенные результаты: к концу 2016 г. Китай экспортировал 35 тыс. т редкоземельных материалов (на 50\% больше по сравнению с 2015 г.). Процесс консолидации отрасли продолжается, и на данный момент основные организационные проблемы связаны с разделением полномочий центральных властей и провинций.

Важнейшей особенностью китайской РЗМ-отрасли является особый характер формирования цепочек добавленной стоимости в экономике - неуклонно растет доля добавленной 
стоимости, созданной внутри страны (по сравнению с другими странами). В частности, на это указывает исследование Института экономики переходного периода Банка Финляндии [Simola, 2017], в котором отмечено, что еще 10 лет назад модель роста в Китае в значительной степени опиралась на инвестиции и связанную с ними тяжелую промышленность. Однако в последние годы эта модель роста утратила прежнюю значимость, и китайская экономика постепенно перешла к модели, основанной на росте потребления. Этот фактор, а также стремительный рост доходов, способствовали развитию сектора внутренних услуг.

Дальнейшие шаги Китая в сфере поддержки внутреннего спроса на РЗМ отражены в принятой в 2015 г. национальной промышленной стратегии «Сделано в Китае-2025» (Made in China-2025³). В частности, политика в области Р3М создала технологическую и ресурсную основу для ее реализации. Стратегия направлена на модернизацию национального производства и задает ориентировочные ключевые показатели для развития внутреннего производства в 10 отраслях промышленности, продукция которых должна занять 80\% внутреннего рынка. Предусматривается достижение полной технологической независимости Китая: от производства чипов до выпуска беспилотных автомобилей.

Эволюция политики Китая в управлении РЗМ-промышленностью наглядно показывает принципиальное отличие в подходах от стран с развитой экономикой и современной индустрией (прежде всего, ЕС и США). Западные игроки в значительной степени полагаются на действие глобальных рыночных механизмов: технологическая цепочка в этом секторе рассматривается как глобальная, в которой разные страны берут на себя специализацию на ее отдельных этапах в зависимости от экономической целесообразности. В то время как Китай на протяжении последних десятилетий развивал технологии добычи, обогащения и разделения, а также создавал высокотехнологичные отрасли потребления РЗМ, ориентируясь на получение технологических

${ }^{3}$ URL: https://www.merics.org/sites/default/files/2017-09/MPOC_No.2_MadeinChina2025. pdf 
и экономических преимуществ в рамках замкнутой технологической цепочки.

\section{Рост спроса на наукоемкие изделия - стимул к применению РЗМ}

Спрос на РЗМ является производным, отличающимся от спроса на потребительские товары. РЗМ используются в качестве технологического компонента, а спрос на них определяется уровнем производства конечных продуктов с высокой добавленной стоимостью (плоские дисплеи, автомобили, катализаторы и т.д.). В результате спрос на РЗМ зависит от технологического развития и темпов экономического роста в стране.

Под влиянием экономического роста и увеличения потребительского спроса Китай наращивает объемы внутреннего выпуска Р3М. Приведем один пример. Активное развитие ветровой энергетики в стране предъявляет повышенный спрос на постоянные неодимовые магниты (рис. 3). В ближайшие 10 лет Китай планирует ежегодно вводить в строй более 25 ГВт ветряных электростанций, установленная мощность ветроэнергетики должна достигнуть в стране 403 ГВт (это почти вдвое больше, чем сегодняшняя мощность всей российской электроэнергетики $)^{4}$.

\begin{tabular}{|c|c|c|c|c|c|}
\hline & $\begin{array}{c}\text { Добыча } \\
\text { руды }\end{array}$ & $\begin{array}{c}\text { Рудный } \\
\text { концентрат }\end{array}$ & $\begin{array}{l}\text { Производство } \\
\text { оксидов }\end{array}$ & $\begin{array}{c}\text { Производство } \\
\text { чистых } \\
\text { металлов }\end{array}$ & $\begin{array}{c}\text { Производство } \\
\text { неодимовых } \\
\text { магнитов } \\
\end{array}$ \\
\hline Китай & $\mathrm{x}$ & $8^{*}$ & 11 & 7 & 9 \\
\hline Австралия & $\mathrm{x}$ & 1 & & & \\
\hline Индия & $\mathrm{x}$ & 1 & & & \\
\hline Россия & $\mathrm{x}$ & 1 & 1 & & \\
\hline Европа & & 1 & 2 & 2 & 1 \\
\hline Япония & & & & 5 & 5 \\
\hline
\end{tabular}

* - число компаний по странам

Puc. 3. Место различных стран в технологической цепочке производства неодимовых магнитов

${ }^{4}$ URL: http://renen.ru/after-10-years-china-s-wind-energy-will-exceed-400-gw/ 
Отметим, что Китай - единственная страна, которая контролирует всю цепочку производства неодимовых магнитов. Технологические компетенции России в этом секторе рынка ограничены производством оксидов и дальнейшим экспортом полупродуктов. Также очевидна стратегия Японии - не имея собственных источников РЗМ, диверсифицировать источники поставки оксидов из других стран и выпускать продукцию с высокой добавленной стоимостью.

Итак, политика Китая заключается в создании своей отечественной обрабатывающей промышленности, ее участии на всех этапах технологической цепочки и привлечении иностранных инвесторов к организации своих производств в стране. Со своей стороны Китай готов предложить доступ к РЗМ, металлам и сплавам, а также доступ к развивающемуся китайскому рынку.

\section{Российская РЗМ-отрасль - чему учит опыт Китая?}

Важнейшая проблема развития в России производства редкоземельных металлов - это низкий уровень их потребления внутри страны. В отсутствие спроса не развивается предложение РЗМ, которое в настоящее время представлено только Соликамским магниевым заводом - остальные закрылись или остались за пределами России (всего в советской редкоземельной отрасли было девять крупных предприятий). Исходя из опыта Китая, создаваемая в России отрасль должна найти ответ на фундаментальный вопрос: как соединить сырьевой поток и рынок потребителей/производителей высокотехнологичных изделий (т.е. сбалансировать предложение и спрос). Именно на решении этой проблемы делал первоочередной акцент Китай. Сравнительный анализ направлений и подходов к развитию редкоземельной отрасли в Китае и в России приведен в таблице 1 .

Для ответа на вопрос о возможном пути становления и развития российской редкоземельной отрасли необходимо понимание того, что исторически в структурном плане отрасль развивалась совершенно по-разному в нашей стране и в Китае в разных направлениях: 
Таблица 1. Сравнительный анализ динамики развития редкоземельной отрасли в Китае и в России в 1980-2018 гг.

\begin{tabular}{|c|c|c|c|c|}
\hline & & 1980 & 2000 & 2018 \\
\hline \multirow{4}{*}{ Россия } & $\begin{array}{l}\text { 1. Количество предприятий } \\
\text { (динамика) }\end{array}$ & $\begin{array}{l}9 \text { крупных пред- } \\
\text { приятий }\end{array}$ & $\begin{array}{l}\text { Дробление и за- } \\
\text { крытие компаний }\end{array}$ & $\begin{array}{l}\text { Создание госком- } \\
\text { паний «полного } \\
\text { цикла» }\end{array}$ \\
\hline & $\begin{array}{l}\text { 2. Степень горизонтальной/ } \\
\text { вертикальной интеграции }\end{array}$ & \multicolumn{3}{|c|}{$\begin{array}{l}\text { От вертикальной к горизонтальной интеграции (рост экс- } \\
\text { порта полупродуктов, понижение переделов, выполняемых } \\
\text { внутри страны) }\end{array}$} \\
\hline & 3. Спрос на РЗМ внутри страны & \multicolumn{3}{|c|}{$\begin{array}{l}\text { От высокого спроса книзкому (непоследовательнаяполитика } \\
\text { государства в области создания спроса, рост импорта РЗМ) }\end{array}$} \\
\hline & $\begin{array}{l}\text { 4. Основные меры государствен- } \\
\text { ной политики }\end{array}$ & $\begin{array}{l}\text { Планирование } \\
\text { производства } \\
\text { и потребления } \\
\text { Р3М }\end{array}$ & \multicolumn{2}{|c|}{$\begin{array}{l}\text { C } 2016 \text { г. - меры стимулирования } \\
\text { отрасли (Подпрограмма 15), акцент } \\
\text { на формирование предложения Р3М }\end{array}$} \\
\hline \multirow{4}{*}{ Китай } & $\begin{array}{l}\text { 1. Количество предприятий } \\
\text { (динамика) }\end{array}$ & $\begin{array}{l}\text { Большое число } \\
\text { малых компаний } \\
\text { (артелей) }\end{array}$ & $\begin{array}{l}\text { Консолидация } \\
\text { компаний при } \\
\text { государственном } \\
\text { участии }\end{array}$ & $\begin{array}{l}\text { Небольшое число } \\
\text { крупныхкомпаний } \\
\text { (добыча и произ- } \\
\text { водство разде- } \\
\text { лены) }\end{array}$ \\
\hline & $\begin{array}{l}\text { 2. Степень горизонтальной/ } \\
\text { вертикальной интеграции }\end{array}$ & \multicolumn{3}{|c|}{$\begin{array}{l}\text { От горизонтальной квертикальной интеграции (повышение } \\
\text { глубины переработки РЗМ-концентратов выполняемой } \\
\text { внутристраны, наращиваниеэкспортавысокотехнологичной } \\
\text { Р3М-продукции) }\end{array}$} \\
\hline & 3. Спрос на РЗМ внутри страны & \multicolumn{3}{|c|}{ Рост уровня развития хайтека (внутреннего спроса на РЗМ) } \\
\hline & $\begin{array}{l}\text { 4. Основные меры государствен- } \\
\text { ной политики }\end{array}$ & $\begin{array}{l}\text { Применение мер } \\
\text { протекционизма } \\
\text { (пошлины, квоты) }\end{array}$ & \multicolumn{2}{|c|}{$\begin{array}{l}\text { Меры стимулирования внутреннего } \\
\text { спроса на хайтек продукцию, стимули- } \\
\text { рование локализации высокотехноло- } \\
\text { гичных зарубежных РЗМ-производств }\end{array}$} \\
\hline
\end{tabular}

- Китай: от множества мелких и средних компаний к крупным отраслевым объединениям; от участия в горизонтальных цепочках - к вертикальным;

- Россия: от развитой РЗМ-промышленности - к практически полной ликвидации отрасли и этапу восстановления, в том числе на основе новых сырьевых источников; от высокотехнологичных изделий - к экспорту полупродуктов и импорту кондиционных РЗМ.

Учитывая критическое значение РЗМ для высокотехнологичных отраслей, в 2012 г. была сформирована отдельная программа развития отрасли (подпрограмма № 15 «Развитие промышленности редких и редкоземельных металлов» в рамках Госпрограммы «Развитие промышленности и повышение ее конкурентоспособности»).

Однако на данный момент в России нет системного понимания общей картины рынка РЗМ. В частности, подпрограмма № 15 
регулирует только вопросы развития ресурсной базы и технологий. При этом не затрагиваются проблемы создания материалов с новыми потребительскими свойствами за счет применения РЗМ. Тогда как в Китае с 2015 г. реализуется программа «Сделано в Китае-2025», нацеленная именно на развитие и применение новых технологий и материалов, в том числе на основе РЗМ.

Сравнительный анализ аспектов функционирования редкоземельной отрасли в Китае и в России приведен в таблице 2.

\section{Таблица 2. Аспекты функционирования редкоземельной отрасли в Китае и в России в настоящее время}

\begin{tabular}{|c|c|c|}
\hline & Китай & Россия \\
\hline $\begin{array}{l}\text { Территориальное размеще- } \\
\text { ние добывающих и перера- } \\
\text { батывающих мощностей }\end{array}$ & $\begin{array}{l}\text { Редкоземельные предприятия } \\
\text { расположены вблизи крупных шахт, } \\
\text { развитая логистика }\end{array}$ & $\begin{array}{l}\text { Редкоземельные предприятия } \\
\text { удалены от районов добычи, зна- } \\
\text { чительные затраты на логистику }\end{array}$ \\
\hline $\begin{array}{l}\text { Присутствие Р3М в рудах } \\
\text { (преимущественно) }\end{array}$ & Как попутный компонент & $\begin{array}{l}\text { Как основной компонент (прежде } \\
\text { всего, на вводимых в разработку } \\
\text { месторождениях) }\end{array}$ \\
\hline $\begin{array}{l}\text { Преобладающие формыпо- } \\
\text { строения РЗМ-производств }\end{array}$ & $\begin{array}{l}\text { Формированиесвязейдобывающей } \\
\text { компании с компаниями по извле- } \\
\text { чению всех компонентов }\end{array}$ & $\begin{array}{l}\text { Формирование связей на стадии } \\
\text { использования Р3М в высокотех- } \\
\text { нологичных отраслях (желаемый } \\
\text { вариант) }\end{array}$ \\
\hline $\begin{array}{l}\text { Основные меры поддержки } \\
\text { отрасли }\end{array}$ & $\begin{array}{l}\text { Наличие долгосрочной програм- } \\
\text { мы поддержки отрасли (кредиты } \\
\text { и субсидии, поддержка укрупнения } \\
\text { в РЗМ-отрасли, финансоваяподдер- } \\
\text { жка отраслей-потребителей РЗМ) }\end{array}$ & $\begin{array}{l}\text { Реализуется отдельная программа } \\
\text { развития отрасли (в рамках Го- } \\
\text { спрограммы), нацеленная на до- } \\
\text { разведкуместорожденийиразвитие } \\
\text { технологий }\end{array}$ \\
\hline Влияние на цены на РЗМ & $\begin{array}{l}\text { Значительное влияние (из-за мо- } \\
\text { нопольного положения на рынке), } \\
\text { с } 2014 \text { г. ограничено мерами ВТО }\end{array}$ & $\begin{array}{l}\text { Отсутствует (незначительный уро- } \\
\text { вень добычи и потребления) }\end{array}$ \\
\hline $\begin{array}{l}\text { Принцип формирования } \\
\text { технологических цепочек }\end{array}$ & $\begin{array}{l}\text { Вертикальные цепочки полного } \\
\text { цикла }\end{array}$ & 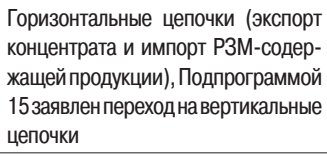 \\
\hline $\begin{array}{l}\text { Ориентация на внутренний } \\
\text { спрос }\end{array}$ & Преобладающая & $\begin{array}{l}\text { Декларируется, но внутренний спрос } \\
\text { крайне незначителен }\end{array}$ \\
\hline $\begin{array}{l}\text { Уровень экологического } \\
\text { регулированиядобычи ипе- } \\
\text { реработки РЗМ }\end{array}$ & $\begin{array}{l}\text { С } 2010-x \text { гг. был ужесточен, но по- } \\
\text { прежнему ниже, чем в западных } \\
\text { странах }\end{array}$ & $\begin{array}{l}\text { Высокий, реализации проектов } \\
\text { предшествует длительная эколо- } \\
\text { гическая экспертиза }\end{array}$ \\
\hline
\end{tabular}

По нашему мнению, с учетом опыта Китая российской редкоземельной отрасли следовало бы ориентироваться на следующие направления.

1. Развитие и стимулирование участия малого и среднего бизнеса в сфере производства РЗМ и выпуска высокотехнологичных 
изделий в рамках вертикальной технологической цепочки. По сути, на данный момент в России элементы такой цепочки присутствуют только у госкорпорации «Ростех».

2. Встраивание в технологические цепочки других стран. Например, Япония проводит активную политику диверсификации источников поставок РЗМ. Емкость рынка, потребляющего РЗМ в Японии, составляет около 25 тыс. т в год, что открывает перед российскими производителями потенциальные возможности по замещению Китая в роли основного экспортера РЗМ в эту страну.

3. Упрощение процедуры внедрения в промышленность результатов НИОКР в области РЗМ-содержащей продукции и технологий. Исполнители НИОКР в рамках Госпрограммы регулярно сталкиваются со сложностями при внедрении результатов разработок в промышленность, что связано со сложности в сфере нормативно-правового регулирования.

4. Создание условий для локализации высокотехнологичных производств в России на основе мер комплексного стимулирования: снижения налоговых льгот, импортных пошлин на ввоз оборудования и компонентов и т.д.

5. Ключевой проблемой РЗМ-отрасли в России является несбалансированность предложения и спроса. Приоритет должен быть отдан решению вопроса не «что и где добывать», а «где и как потреблять и использовать». Для решения этой проблемы необходимо создание технологических центров компетенции с участием частного бизнеса на базе существующих структур подобного рода (технопарков) в городах Сибири. Это позволит воссоздать утраченные связи северных (добывающих) регионов и перерабатывающих регионов Сибири.

6. Из опыта Китая целесообразно применение мер протекционизма и ограничения (снижения стимулов) вывоза концентратов РЗМ для увеличения глубины переработки внутри страны-Китай создал внутренний спрос на РЗМ и только тогда снизил пошлины на вывоз полупродуктов РЗМ низких переделов.

\section{Заключение}

Итак, особенность китайской политики развития производственного и сырьевого потенциала (как в отношении РЗМ, так и других сырьевых товаров) встраивание не в рынки товаров, продуктов или услуг, а в технологические цепочки. Китайское 
доминирование основано на преобладании горизонтальных связей - десятилетиями Китай выходил на рынки со своим сырьем различной степени технологических переделов и промежуточными компонентами. И только в последние 10-15 лет началось выстраивание вертикальных цепочек - «от сырья к высокотехнологичному изделию» - в рамках ориентации на внутренний спрос.

В России в настоящее время считается, что акцент должен непременно делаться на создании «здесь и сейчас» вертикальных цепочек, чтобы в конце получить производство высокотехнологичной продукции. По нашему мнению, подход должен отличаться гибкостью - повторение модели Китая из-засложившихся особенностей представляется затруднительным, следует сочетать различные сценарии и варианты развития. В частности, российская РЗМ-отрасль вполне могла бы стать частью китайских или японских цепочек создания добавленной стоимости, и это взаимодействие необязательно должно быть основано на экспорте необработанного сырья. Однако, следует понимать, что в глобальных цепочках производства высокотехнологичной продукции Россию пока «не ждут» - туда можно войти только дешевой продукцией с малой добавленной стоимостью, что не может рассматриваться как приоритетная цель.

\section{Литература}

Самсонов Н. Ю., Крюков Я. В., Яценко В. А. Проблемы формирования спроса на продукцию Томторского скандий-ниобий-редкоземельного месторождения (Республика Саха (Якутия)) // Вестник Северо-Восточного федерального университета им. М.К. Аммосова. Серия «Экономика. Социология. Культурология» [Эл. ресурс]. 2016. № 4. С. 5-11.

Barakos G., Mischo H., Gutzmer J., Legislation; challenges and policy strategies: in search for a regulatory framework for sustainable development in the rare earths mining industry// Conference: SME Annual Meeting and Mining Engineering. Conference Paper. - Project: Mining Valuation of REE deposits. At: Phoenix, Arizona, USA. - February 2016.

Jung, Alexander, and Weiland Wagner. Rare Earths: High-Tech Companies Face Shortages as China Hoards Metals. Speigel Online. 138 References Speigel Online, 11 May 2009. Web. 08 May 2012.

Michael G. Pecht, Robert E. Kaczmarek, Xin Song, Dylan A. Hazelwood, Robert A. Kavetsky, Davinder K. Anand. Rare Earth Materials: Insights and Concerns, 2012, University of Maryland, College Park, Maryland.

Shen Lei, Wu Na, Zhong Shuai, Gao Li. Overview on China's Rare Earth Industry Restructuring and Regulation Reforms. Journal of Resources and Ecology, 2017, Vol. 8 No.3. Pp.213-222. 
Simola $H$. Chinese production chains rely increasingly on domestic services. Bank of Finland (BOFIT), Institute for Economies in Transition, BOFIT Policy Brief 4/2017, 18 April 2017.

Статья поступила 20.08.2018.

\section{Summary}

Kryukov Ya.V., Samsonov N. Yu., Yatsenko V.A., Institute of Economics and Industrial Engineering, SB RAS, Novosibirsk

\section{Russian Rare Earth Industry: Should China's Experience be Adopted?}

The most important feature of China's policy in national rare-earth industry is the creation of technological chains "from raw materials to high-tech products" with orientation on domestic demand only. Russia now faces the problem of choosing the way of how to develop the rare earth industry, and in experience of China, can be useful. In particular, this is relevant because of the beginning of the Tomtor niobiumrare-earth deposit development. However Russian approach should be flexible and combine various instruments of industrial and trade policy. It would be difficult to introduce the instruments of such a policy used in China because of the national specifics and different starting conditions for building a rare-earth industry in Russia and China. Russia should enter into global chains of high-tech products based on rare earths, and the first is a stimulation of domestic demand for high-tech products and components. China's experience seems to be useful there.

Rare earth metals; China, high-tech products; demand stimulation; industrial policy; innovation; technological chains

\section{References}

Samsonov N.Yu, Kryukov Ya. V., Yatsenko V.A. (2016) Problemy formirovaniya sprosa na produkciyu Tomtorskogo skandij-niobij-redkozemelnogo mestorozhdeniya (respublika Saha (Yakutiya)). Vestnik Severo-vostochnogo federalnogo universiteta im. M.K. Ammosova. seriya Ekonomika. sociologiya. Kulturologiya. No. 4. Pp. 5-11. (In Russ.)

Barakos G., Mischo H., Gutzmer J. (2016) Legislation; challenges and policy strategies: in search for a regulatory framework for sustainable development in the rare earths mining industry. Conference: SME Annual Meeting and Mining Engineering. Conference Paper. Project: Mining Valuation of REE deposits. At: Phoenix, Arizona, USA. February.

Jung, Alexander, and Weiland Wagner. Rare Earths: High-Tech Companies Face Shortages as China Hoards Metals. Speigel Online. 138 References Speigel Online, 11 May 2009. Web. 08 May 2012.

Michael G. Pecht, Robert E. Kaczmarek, Xin Song, Dylan A. Hazelwood, Robert A. Kavetsky, Davinder K. Anand. (2012) Rare Earth Materials: Insights and Concerns, University of Maryland, College Park, Maryland.

Shen Lei, Wu Na, Zhong Shuai, Gao Li. (2017) Overview on China's Rare Earth Industry Restructuring and Regulation Reforms. Journal of Resources and Ecology, Vol. 8. No.3. Pp.213-222.

Simola H. (2017) Chinese production chains rely increasingly on domestic services. Bank of Finland (BOFIT), Institute for Economies in Transition, BOFIT Policy Brief 4/2017, 18 April. 